Historic, Archive Document

Do not assume content reflects current scientific knowledge, policies, or practices. 



\section{Cactus Moth (Cactoblastis cactorum)}

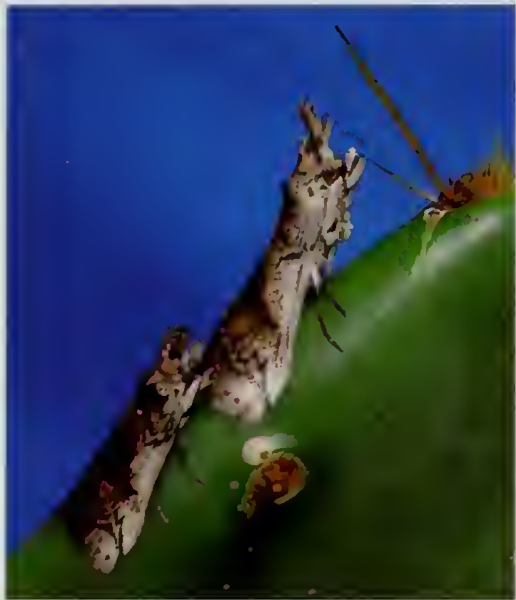

Adult cactus moths (male on the left; female on the right).

\section{What Is It?}

Adult cactus moths are inconspicuous, brownish-gray moths with two wavy transverse bands on their wing tips.

Females are generally larger than males, and their wings are slightly darker.

Caterpillars of this moth are capable of destroying entire stands of cacti with their feeding. The moths feed exclusively on prickly pear cacti, thereby threatening native landscapes and agricultural industries in the Southern United States and Mexico.

\section{Where Did It Come From?}

The cactus moth occurs naturally in the northern parts of Argentina, in Uruguay and Paraguay, and in the southern

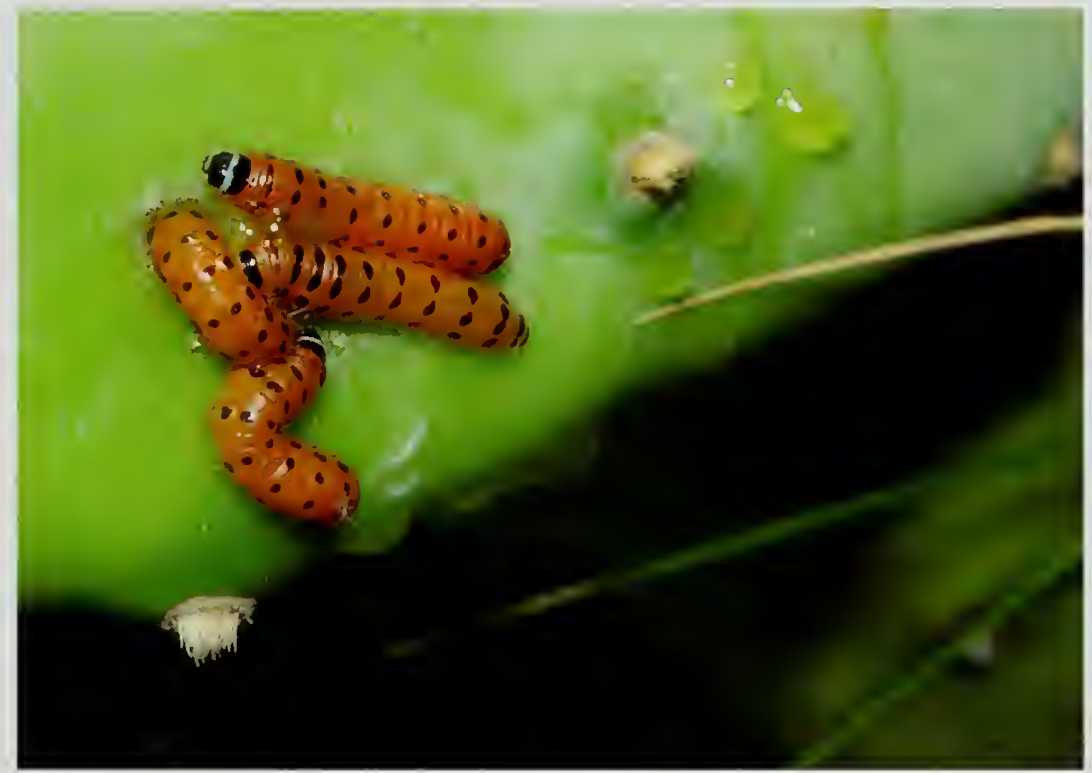

Cactus moth larvae.

parts of Brazil. The moth was introduced into Australia and South Africa, and from there spread to the Caribbean islands and the United States. Cactus moths are now found in Alabama, Florida, Georgia, and South Carolina.

\section{What To Look for and Where To Look}

1. Check for Larvae. Adult moths are difficult to identify without dissection. So the best detection strategy is to look for the cactus moth's distinctive larvae. Mature larvae are reddish-orange with blackish spots forming transverse bands. In larvae in their final (sixth) instar, these transverse bands are nearly always divided into spots.
2. Check for Egg Sticks. Between late February and November, adult cactus moths lay chains of eggs called egg sticks that resemble the naturally occurring spines on prickly pear pads. The egg sticks are initially cream colored but darken to brown, and later almost black, shortly before the larvae emerge. The egg sticks are distinguished from spines by their curved appearance. An egg stick with about 70 eggs is approximately $2.4 \mathrm{~cm}$ (nearly 1 inch) long. Other native prickly pear-feeding moth species in the genus Melitara also lay their eggs in sticks. Their egg sticks cannot reliably be distinguished from those of the cactus moth. 


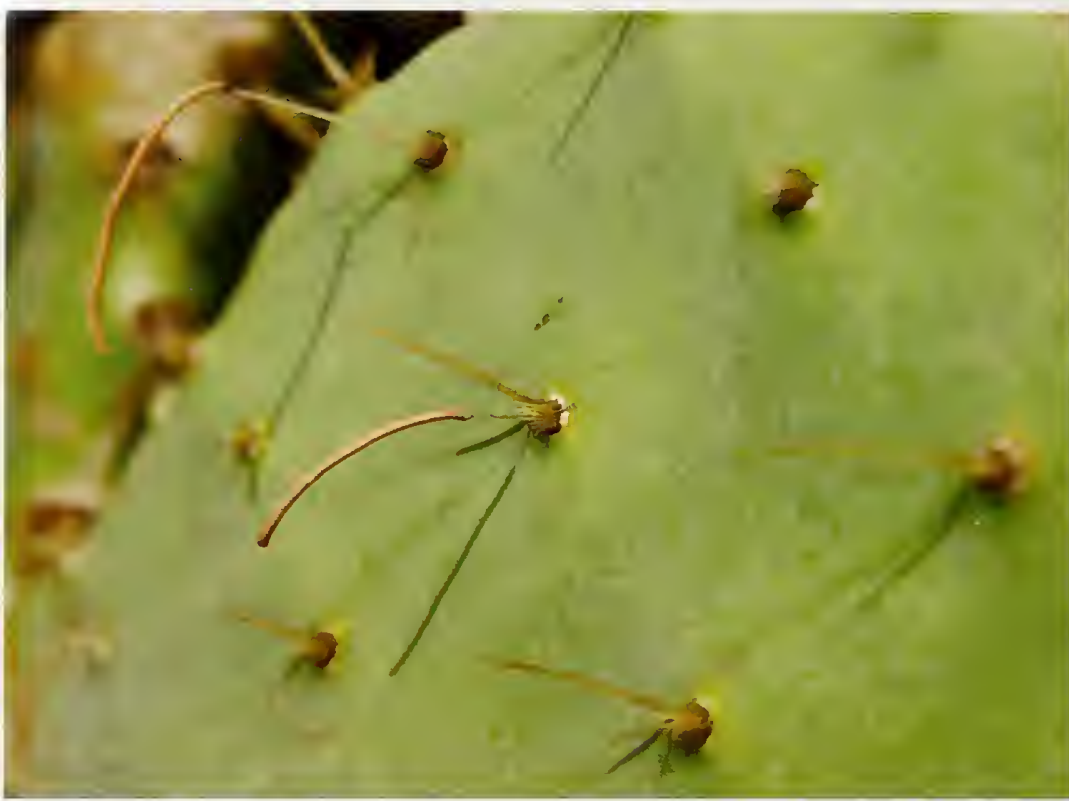

Cactus moth egg stick.

3. Check for Hollowed Cactus Pads. Cactus moth larvae live and feed communally inside the pads of prickly pear cacti. Damaged pads will show characteristic oozing of internal plant juices and insect droppings. The cactus moth has been found to eat most prickly pear cactus with flat pads in the genus Opuntia. However, the members of the genus Opuntia known as "cholla" cactus are not normally hosts of the cactus moth.

\section{How Does it Spread?}

Adult cactus moths have been known to disperse a maximum of about $24 \mathrm{~km}$ (16 miles).

Over longer distances, trade in infested cacti could spread the larvae and eggs.

\section{Where Should I Report Cactus Moth Sightings?}

There are other species of cactus-feeding larvae that are native to the United States. These native species may be confused for the exotic species, so proper identification is important. To have a specimen properly identified, please contact your State department of agriculture or the entomology department at your local landgrant university.

For information about the cactus moth and its impact on prickly pear cacti, please visit <http://www.aphis.usda.gov/ppq/ ep/emerging_pests/cactoblastis/ index.html>.

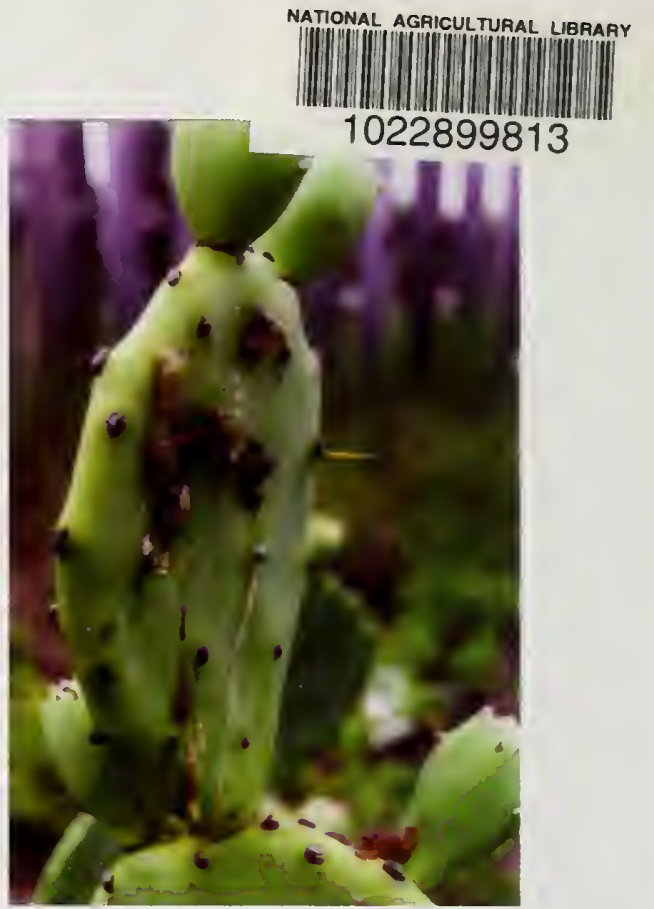

Damage to prickly-pear cactus pad caused by larvae of the cactus moth.

The U.S. Department of Agriculture is an equal opportunity provider and employer.

Photo credits: The photograph of the damaged prickly pear cactus was taken by Joel Floyd of USDA-APHIS-Plant Protection and Quarantine. The remaining images were shot by Ignacio Baez, a biological science technician with USDA's Agricultural Research Service.

\section{United States}

Department of Agriculture Animal and Plant Health Inspection Service

Program Aid No. 1879

Issued August 2005

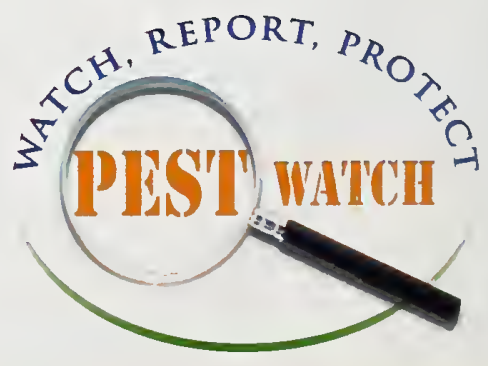

